\title{
The effect of Rotor Separation on the Performance of a Dual Rotor Wind Turbine
}

\author{
ANTHONY ADEYANJU1 ${ }^{1}$ Omar Mohammed ${ }^{2}$, and Krishpersad Manohar ${ }^{3}$ \\ ${ }^{1}$ The University of the West Indies at Saint Augustine Faculty of Engineering \\ ${ }^{2}$ The University of the West Indies at St Augustine \\ ${ }^{3}$ The University of the West Indies St Augustine Campus
}

April 10, 2021

\begin{abstract}
This study conducted simulation and experimental analysis on a dual rotor horizontal axis wind turbine to determine the effect of rotor separation on its performance. An air study was conducted to optimize the turbine blades to a local climate of Trinidad, it was determined that a NACA 64-315 air foil would be the most optimum for the conditions. QBlade software was used for the simulation, the power flow performance for multiple iterations of wind speed was found for the design. The effect of rotor separation on the performance of the dual rotor wind turbine was studied with rotor separation $0.25 \mathrm{~m}$ to $3.0 \mathrm{~m}$ at an interval of $0.25 \mathrm{~m}$ and it was discovered that the smallest rotor separation $0.25 \mathrm{~m}$ shows the largest tip speed ratio, while the largest rotor separation distance $3 \mathrm{~m}$ has the smallest tip speed ratio at a fan speed of $1 \mathrm{~m} / \mathrm{s}$. Also, as the rotor separation decreases the power coefficient (C P ) and the total power increase, which resulted to high energy output of the DRHAWT. This result is valid for the QBlade simulations and the experimental results.
\end{abstract}

\section{Hosted file}

Adeyanju Manuscript-Dual Rotor Wind Turbine-WILEY.pdf available at https://authorea.com/ users/406952/articles/517429-the-effect-of-rotor-separation-on-the-performance-of-adual-rotor-wind-turbine 